\title{
Good Long-Term Glycemic Compensation Is Associated With Better Trabecular Bone Score in Postmenopausal Women With Type 2 Diabetes
}

\author{
P. JACKULIAK ${ }^{1}$, M. KUŽMA ${ }^{1}$, Z. KILLINGER ${ }^{1}$, J. PAYER ${ }^{1}$ \\ ${ }^{1} 5$ th Department of Internal Medicine, Faculty of Medicine, Comenius University Bratislava, \\ University Hospital Bratislava, Bratislava, Slovak Republic
}

Received August 1, 2019

Accepted October 8, 2019

\begin{abstract}
Summary
Osteoporosis is an increasingly widespread disease, as well as diabetes mellitus. It is now accepted that osteoporotic fractures are a serious co-morbidity and complication of diabetes. Despite of good bone mineral density in Type 2 Diabetes (T2DM) patients is the fracture risk elevated. It is due to reduced bone quality. To determine the effect of glycemic compensation on bone density and trabecular bone score (TBS) in T2DM. We analyzed a cohort of 105 postmenopausal women with T2DM. For all patients, central bone density (spinal and lumbar spine) was tested by DXA methodology, glycemic control parameters were assessed, and anthropometric parameters were measured. Bone quality was analyzed using TBS software. The results were statistically processed. Good glycemic compensation with glycated hemoglobin (A1c) value $<7.0 \%$ DCCT did not lead to BMD changes in patients with T2DM. However, patients with HbA1C $<7 \%$ DCCT had significantly better TBS (1.254 \pm 0.148 vs. $1.166 \pm 0.094, p=0.01)$. There was a negative correlation between TBS and glycated hemoglobin $(r=-0,112, p<0.05)$ with glycemic fasting $(r=-0.117, p<0.05)$. The optimal effect on TBS is achieved when all three markers of glycemic compensation (glycated hemoglobin, fasting plasma glucose and postprandial glycemia) are in optimal range. By using ROC curves glycated hemoglobin has the most significant effect on TBS. Optimal glycemic compensation, evaluated by glycated hemoglobin, does not lead to changes in BMD but has a beneficial effect on TBS in T2DM. Good glycemic control is required also for reduction of the risk of osteoporosis and osteoporotic fractures.
\end{abstract}

\section{Key words}

Osteoporosis - Diabetes mellitus - Fractures - Bone quality • Glycemic compensation

\section{Corresponding author}

P. Jackuliak, $5^{\text {th }}$ Department of Internal Medicine, Faculty of Medicine, Comenius University, University Hospital Bratislava, Ruzinovska 6, 82606 Bratislava, Slovac Republic. Email: peter.jackuliak@gmail.com

\section{Introduction}

The numerous complications and comorbidities associated with long-standing diabetes mellitus (DM) contributes to the huge impact of the disease. Many clinical studies have investigated the association between diabetes mellitus and osteoporosis, given that these disorders affect a large proportion of, mostly elderly, population. Although bone mineral density (BMD) is considered as a gold standard for evaluating fracture risk in non-DM osteoporosis, accumulating evidence has shown that patients with type 2 diabetes (T2DM) have a high fracture rate without BMD reduction (Raška et al. 2017). A meta-analysis has shown that T2DM patients have greater hip BMD in comparison to non-DM controls, despite an increased risk of hip fracture (1.4-fold), suggesting that BMD value does not reflect bone fragility in T2DM (Vestergaard 2007). In clinical practice, another information about bone fragility and strength could be provided by trabecular bone score (TBS), an indirect measure of bone microarchitecture, has been useful in indicating poor bone quality in T2D patients with non-osteoporotic BMD. It was observed, that lower TBS value is correlated with lower number and connectivity of trabeculae, and a higher risk of fracture (Hans et al. 2011, Silva et al. 2014). In the sub-cohort of 
diabetics from Manitoba study the lower TBS has been associated with higher fracture risk (Farr et al. 2014). In addition, in the study performing in vivo microindentation analysis on $30 \mathrm{~T} 2 \mathrm{DM}$ postmenopausal women the bone material strength (BMS) was lower than in controls and the glycated hemoglobin (A1c) previous 10 years was negatively related to BMS (Leslie et al. 2013). TBS has a main role in the identification of individuals at risk of fragility fracture particularly in a context of secondary osteoporosis as in diabetic patients. This tool, in fact, seems to have a diagnostic accuracy comparable to that of TBS-adjusted FRAX to discriminate osteoporotic fractures in T2DM postmenopausal women (Bonaccorsi et al. 2017).

Optimal glycemic control is fundamental to the management of diabetes (Žofková 2015). In epidemiological analyses, glycated hemoglobin (A1C) levels $>7.0 \%$ are associated with a significantly increased risk of both microvascular and macrovascular complications, regardless of underlying treatment (Stratton et al. 2000). Data from large diabetic trial demonstrated a continuous relationship between A1C and diabetes complications, with no apparent threshold of benefit. In the DCCT, a $10 \%$ reduction in $\mathrm{A} 1 \mathrm{C}$ was associated with a $40 \%$ to $50 \%$ lower risk of retinopathy progression, although the absolute reduction in risk was substantially less at lower A1C levels (DCCT 1993, Genuth 2006). Both fasting plasma glucose (FPG) and postprandial plasma glucose (PPG) are directly correlated to the risk of complications, with some evidence that postprandial might constitute a stronger risk factor for cardiovascular complications (Sarwar et al. 2010). Epidemiological studies have confirmed that hyperglycemia is the most important factor in the onset and progress of vascular complications, both in T1DM and also T2DM. The formation of advanced glycation end-products (AGEs) correlates with glycemic control (Jakus et al. 2004). The AGE hypothesis proposes that accelerated chemical modification of proteins by glucose during hyperglycemia contributes to the pathogenesis of diabetic complications including nephropathy, retinopathy, neuropathy, atherosclerosis and also bone metabolism (Kalousova et al. 2002).

We performed the cross-sectional study to determine bone mineral density (BMD) and trabecular bone score (TBS), simple indirect surrogate of bone strength, with regard to glycemic control according to A1c, fasting plasma glucose (FPG), 2-hours postprandial plasmatic glucose (PG) in postmenopausal women with
T2DM (Farr et al. 2014).

\section{Methods and Subjects}

\section{Study population}

This cross-sectional study evaluates a cohort of 105 postmenopausal women with T2DM during January - December 2015. The study protocol was reviewed and approved by Comenius University research board. All patients signed informed consent prior to the conduct of any study procedure. The diagnosis of diabetes mellitus was confirmed according diagnostic criteria of American Diabetes Association 2015 (Table 1) using the value of fasting plasma glucose and/or A1C in medical report of the patient (2015).

Table 1. Criteria for the diagnosis of diabetes (2015)

\begin{tabular}{ll}
\hline A1C & $\geq 6.5 \% \mathrm{DCCT}$ \\
Fasting plasma glucose (FPG) & $\geq 7.0 \mathrm{mmol} / 1$ \\
2-h plasma glucose during an OGTT & $\geq 11.1 \mathrm{mmol} / 1$ \\
A random plasma glucose & $\geq 11.1 \mathrm{mmol} / 1$
\end{tabular}

Study inclusion criteria were as follows:

- Subjects with T2DM diagnosed according to the guidelines of the American Diabetes Association 2015 (2015).

- $\quad$ Patients treated only by a stable (minimal 6 months) and maximal tolerated dose of oral antidiabetic drugs metformin and DPP-4 inhibitor sitagliptin. These drugs should have no effect on BMD or risk of fractures (Ceccarelli et al. 2013, Gilbert et al. 2015, Chandran 2017).

- No presence of osteoporosis or treatment for osteoporosis with any antiresorptive drug or supplementation with vitamin $\mathrm{D}$ and calcium.

- No cause of secondary osteoporosis other than T2DM (e.g. malabsorption, rheumatoid arthritis, corticosteroid-induced osteoporosis, etc.) or any other chronic illness which could considerably confound the results of bone measures

From observation were excluded patients:

- With other potential causes of secondary osteoporosis (rheumatoid arthritis, osteogenesis imperfecta in adults, type 1 diabetes, untreated long-standing hyperthyroidism, hypogonadism or premature menopause $<45$ years, chronic malnutrition, or 
malabsorption and chronic liver disease).

- With history of any glucocorticoid treatment.

- No presence or history of hormone replacement therapy.

\section{Outcome measures}

Basic anthropometric measurements of height, weight, waist circumference, and body mass index (BMI) were assessed.

BMD of the lumbar spine (LS), at L1-L4, and total hip (TH) were measured using Hologic Discovery device with identical software (v.12.3 - Hologic Inc., Marlborough, MA, USA).

TBS measurement was derived from L1-L4 DXA scans using TBS iNsight ${ }^{\circledR}$ software (Medimaps group, Geneva, Switzerland) version 3.0.2.0.

Using a questionnaire data about clinical fragility fracture was collected. Prior major fragility fracture was defined as a low-trauma fracture at the hip, vertebral, proximal humerus, and radius that occurred after the age of 40 years. All patient-reported fractures were documented with the appropriate medical record from surgeon or traumatologist. Asymptomatic vertebral fractures have not been actively searched in this study.

Measurement of the plasma concentrations of glucose after 8-hour fasting, 2-hours postprandial PG and A1C were performed in the central hospital laboratory. A1C was measured using ion-exchange high-performance liquid chromatography (HPLC). FPG was measured in venous plasma and hexokinase/Glucose-6-phosphate dehydrogenase has been used for the determination of plasma glucose levels.

According the diabetic guidelines a reasonable A1C goal for adults is $<7 \%$ (2017b). Using this cutpoint we divided the cohort in two subgroups: subjects with A1c $\leq 7.0 \%$ and A1c $\geq 7.1 \%$. Additionally, the analysis of the effect of one, two or all three glycemic compensation parameters on bone parameters in the comparison model 1,2 and 3 , respectively was performed.

For evaluation of glycemic compensation we used the value of $\mathrm{A} 1 \mathrm{C} \leq 7.0 \%, \mathrm{FPG}<7.2 \mathrm{mmol} / \mathrm{l}$ and PPG $<10 \mathrm{mmol} / \mathrm{l}$ according to position statement of the American Diabetes Association and the European Association for the Study of Diabetes (Table 2) (Inzucchi et al. 2015).

\section{Statistical analysis}

The statistical analysis was performed using the
IBM SPSS Statistics 19 software. Numeric data were expressed as means \pm standard deviations (SDs). All parameters were check for normality. The statistical significance of differences in TBS and BMD was than tested by paired t-test or other appropriate test if the parameters were not normal. Between-group variances were assessed by one-way ANOVA or independent sample T-test. A linear regression model to compare predictors of primary outcome change was used. Correlations were assessed by the Pearson correlation test. Tests were adjusted for potential confounding factors when appropriate. The parameter of glycemic compensation with the highest power to TBS was estimated and compared using the receiver operator characteristic (ROC) curve analysis.

Table 2. Summary of glycemic recommendations for adults with diabetes (Inzucchi, et al. 2015)

\begin{tabular}{lc}
\hline AlC (DCCT) & $<7.0 \%$ \\
Preprandial capillary plasma & $4.4-7.2 \mathrm{~mol} / \mathrm{l}$ \\
glucose & \\
Peak postprandial capillary & $10.0 \mathrm{mmol} / \mathrm{l}$ \\
plasma glucose & \\
\hline
\end{tabular}

\section{Results}

\section{Study group characteristics}

Analysis included 105 female patients with T2DM, mean age 54.3 \pm 7.1 years (mean BMI 33.1 \pm $5.3 \mathrm{~kg} / \mathrm{m}^{2}$ ). All subjects were treated with metformin (median dose $1500 \mathrm{mg}$ ) and sitagliptin (dose of $100 \mathrm{mg}$ ), respectively. The study group characteristics are shown in Table 3 and 4. Mean values for A1C, FPG and $2 \mathrm{~h}$ postprandial glucose was $7.6 \pm 0.5 \%, \quad 7.31 \pm$ $1.73 \mathrm{mmol} / \mathrm{l}$, and $9.16 \pm 0.96 \mathrm{mmol} / \mathrm{l}$, respectively.

According to WHO classification, $59.5 \%$ of patients with low bone mass (T-score $\leq-1.0>-2.5)$ and $29.8 \%$ with BMD osteoporosis was present, with no differences in the individual characteristics between these two groups. In the group of patients with osteoporosis, there was a trend towards higher $\mathrm{A} 1 \mathrm{C}$ and a longer duration of DM $(p=0.051)$.

\section{Effect of glycemic compensation on BMD and TBS}

There were no statistical significant differences in BMD according to A1c. Patients with $\mathrm{A} 1 \mathrm{C} \leq 7.0 \%$ showed higher TBS value than patient with $\mathrm{A} 1 \mathrm{C} \geq 7.1 \%$ 
(1.254 \pm 0.148 vs. $1.166 \pm 0.094 ; p=0.01)$ (Table 4). The statistical significant difference was also after adjusting TBS for BMI.

Table 3. Basic characteristics

\begin{tabular}{lc}
\hline Number of subjects & 105 \\
Age (years $) \pm S D$ & $54.3 \pm 7.1$ \\
Height $(\mathrm{cm}) \pm S D$ & $164.27 \pm 9.7$ \\
Weight $(\mathrm{kg}) \pm S D$ & $89.3 \pm 10.2$ \\
$B M I\left(\mathrm{~kg} / \mathrm{m}^{2}\right) \pm S D$ & $33.1 \pm 5.3$ \\
$F N B M D\left(\mathrm{~g} / \mathrm{cm}^{2}\right) \pm S D$ & $0.896 \pm 0.01$ \\
$L S B M D\left(\mathrm{~g} / \mathrm{cm}^{2}\right) \pm S D$ & $1.065 \pm 0.009$ \\
$T B S \pm S D$ & $1.185 \pm 0.153$ \\
Duration of diabetes (years $\pm S D)$ & $5.3 \pm 3.8$ \\
Alc $(\%$ DCCT) & $7.6 \pm 0.5$ \\
Mean duration of menopause & $6.2 \pm 3.3$ \\
(years $\pm S D)$ & \\
Age in time of menopause & $47.7 \pm 3.9$ \\
(years) $\pm S D)$ & $14(13.3 \%)$ \\
Clinical fractures (n, \%) & \\
\hline
\end{tabular}

BMI - body mass index, FN BMD - femoral neck hip BMD, LS BMD - lumbar spine BMD, BMD - bone mineral density, TBS trabecular bone score

The ROC curves for all the compensation parameters in TBS prediction showed AUC 0.813; 0.745 and 0.611 for A1c, FPG and $2 \mathrm{~h}$ postprandial $\mathrm{PG}$, respectively (Fig. 2).

In the correlation analyses TBS was significantly inversely correlated with A1C and fasting plasma glucose, also after adjusting for BMI. No correlation of TBS and 2-hour postprandial PG was observed (Table 5). Multivariate linear regression analyses revealed that FPG and A1c were significantly associated with decreased TBS.

Positive correlation between A1C BMD (Table 6), BMD and FPG was observed. Mild association between BMD (both sites) and 2-h postprandial PG was observed. The effect of duration of diabetes was not observed, but there was not statistical significant difference in the duration of the disease between the two groups (divided according A1c).

\section{Fractures}

In the whole cohort 14 patients (13.3\%) reported a low trauma clinical fracture -2 hip fractures, 6 fractures of distal forearm, 1 fracture of humerus and 5 ankle fractures. We observed no differences between those with fractures and those without in age, BMD or
BMI. However, those with fractures had higher A1C values $(8.1 \%$ vs $7.5 \% ; p=0.05)$ and lower mean TBS scores $(1.261$ vs $1.305 ; p=0.031)$.

\section{Discussion}

Diabetes-related complications significantly affect patient lives. Therefore, clinicians and their patients need to be aware of common comorbidities that affect people with diabetes and may complicate management (Sudore et al. 2012, Tinetti et al. 2012). Nowadays, fragility fractures are becoming the most challenging problem and serious comorbidity of the diabetes mellitus, especially in type 2 (2017a). This raises questions how fragility fractures in T2DM could be predicted and prevented. It is widely accepted that routine measurement of BMD could not provide the information about the fracture risk, since BMD is normal or even increased in T2DM patients (Burghardt et al. 2010, Farr et al. 2014). Therefore, it is assumed that bone quality and strength play major role in the fracture risk, but previous studies remains inconclusive. Measurement of the bone material strength (BMS; assessed in vivo by microindentation testing) revealed significantly decreased BMS values in diabetics, after multiple adjustments (Farr et al. 2014).

It is recommended that TBS could be used, in addition to BMD, in postmenopausal females with T2DM. Fracture prevention strategies for people with diabetes are the same as for general population but it is necessary to achieve good glycemic compensation. Recently, studies performing bone microidentation showed that BMS values are inversely correlated with disease duration, accumulation of advanced glycation end-products (AGE) (Furst et al. 2016), and with the disease control (expressed as the average A1c concentration for the previous 10 years) (Farr et al. 2014). Therefore, we conducted the study to compare bone measures, BMD and TBS, in postmenopausal T2DM women with regard to glycemic compensation.

We showed that good glycemic compensation with a cut-point of $\mathrm{A} 1 \mathrm{C} \leq 7.0 \%$ does not have any effect on BMD in patients with T2DM. The effect of optimal FPG, as well as optimal $2 \mathrm{~h}$ PPG was not significant. A correlation analysis revealed positive association between the individual glycemic compensation and BMD at both sites. Possible explanation of this correlation is that patients with worse A1c had greater BMI which could overestimate BMD values. 
Table 4. Comparison of the subgroups according to A1C

\begin{tabular}{lccc}
\hline & $\mathbf{A}_{\mathbf{1 c}} \leq \mathbf{7 . 0} \mathbf{0}$ & $\mathbf{A}_{\mathbf{1 c}} \geq \mathbf{7 . 1} \mathbf{\%}$ & $\mathbf{p}$ \\
\hline Number of subjects & 42 & 63 & \\
Age $($ years $) \pm S D$ & $53.2 \pm 6.7$ & $55.4 \pm 7.3$ & N.S. \\
Height $(\mathrm{cm}) \pm S D$ & $163.5 \pm 8.8$ & $164.1 \pm 9.2$ & N.S. \\
Weight $(\mathrm{kg}) \pm S D$ & $87.5 \pm 8.9$ & $92.1 \pm 9.5$ & N.S. \\
BMI $\left(\mathrm{kg} / \mathrm{m}^{2}\right) \pm S D$ & $32.7 \pm 7.8$ & $34.3 \pm 8.9$ & N.S. \\
FN BMD $\left(\mathrm{g} / \mathrm{cm}^{2}\right) \pm S D$ & $0.891 \pm 0.11$ & $0.907 \pm 0.07$ & N.S. \\
LS BMD $\left(\mathrm{g} / \mathrm{cm}^{2}\right) \pm S D$ & $1.061 \pm 0.012$ & $1.072 \pm 0.010$ & N.S. \\
TBS $\pm S D$ unadjusted & $1.254 \pm 0.148$ & $1.166 \pm 0.094$ & 0.01 \\
TBS $\pm S D$ adjusted on BMI & $1.249 \pm 0.141$ & $1.174 \pm 0.099$ & 0.01 \\
Duration of diabetes (years $\pm S D)$ & $5.2 \pm 2.9$ & $5.3 \pm 1.6$ & N.S. \\
Duration of menopause (years $\pm S D)$ & $5.8 \pm 2.5$ & $6.4 \pm 2.2$ & N.S. \\
Clinical fractures $(\mathrm{n}$, \%) & $5(11.9 \%)$ & $9(14.2 \%)$ & 0.051 \\
\hline
\end{tabular}

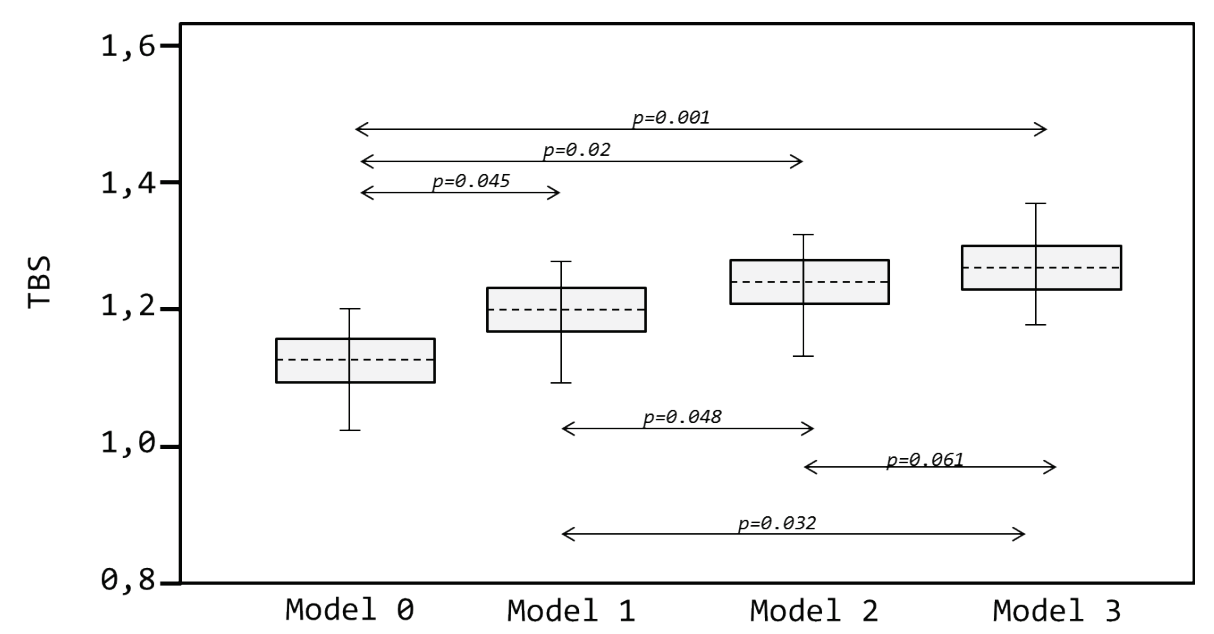

Fig. 1. Comparison of the effect of different models on TBS according to number of glycemic compensation parameters in the "good" range. The greatest TBS was observed when all three compensation parameters were in "good" range. Model 0: No parameter is compensated. Model 1: only 1 good marker (A1C $\leq 7.0 \%$ or FPG $<7.2 \mathrm{mmol} / \mathrm{l}$ or PPG < $10 \mathrm{mmol} / \mathrm{l}$ ), Model 2: two good compensated markers, Model 3: all 3 good compensated markers $(\mathrm{A} 1 \mathrm{C} \leq 7.0 \%$, FPG $<7.2 \mathrm{mmol} / \mathrm{l}$, PPG $<10 \mathrm{mmol} / \mathrm{l})$
Table 5. Correlation analysis between TBS and markers of glycemic compensation

\begin{tabular}{lcc}
\hline & R & p-value \\
\hline A1C-TBS & -0.112 & $<0.05$ \\
Fasting plasma glucose - TBS & -0.127 & $<0.05$ \\
2-h postprandial glucose - TBS & -0.158 & 0.09 \\
\hline
\end{tabular}

Similar association between BMD and A1c was observed in few previous studies (Oei et al. 2015, Oei et al. 2013). In the Rotterdam Study poor glycemic control based on A1C $\geq 7.5 \%$ in T2DM was associated with higher risk of all types fractures, higher BMD, and thicker femoral cortices in narrower bones (Oei et al. 2013). Another study found that T2DM was significantly and independently associated with increased risk of fractures among persons with $\mathrm{HbA} 1 \mathrm{C} \geq 8 \%$ as compared to those individuals with $\mathrm{A} 1 \mathrm{C}$ below $8 \%$ (Schneider et al. 2013).

Table 6. Correlation analysis between BMD and markers of glycemic compensation

\begin{tabular}{llcc}
\hline & & R & p-value \\
\hline AlC & BMD - FN & 0.045 & $<0.05$ \\
& BMD - LS & 0.241 & $<0.05$ \\
Fasting plasma & BMD - FN & 0.039 & 0.07 \\
glucose & BMD - LS & 0.117 & 0.05 \\
2-h postprandial & BMD - FN & 0.036 & 0.05 \\
glucose & BMD - LS & 0.120 & 0.06 \\
\hline
\end{tabular}

BMD-FN: Bone mineral density of femoral neck; BMD-LS: Bone mineral density of lumbar spine; 


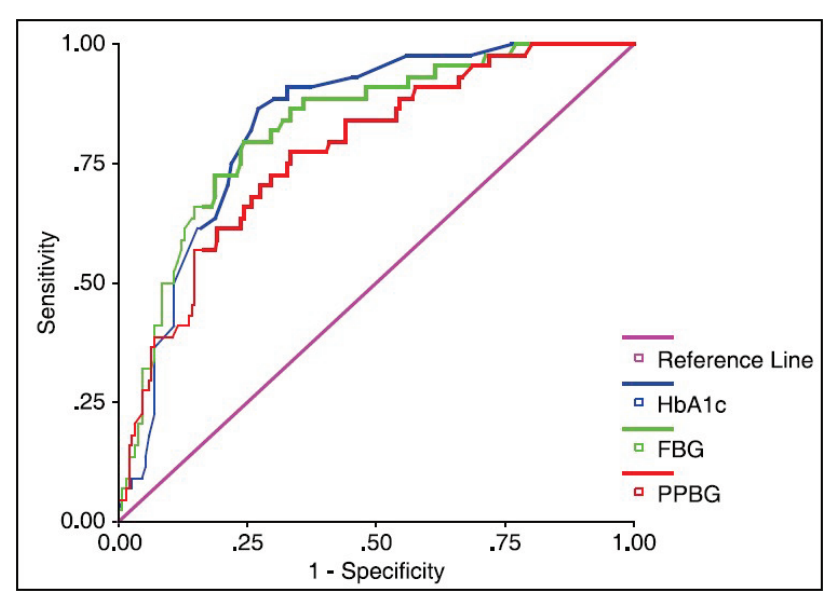

Fig. 2. ROC curve of the effect of "glycemic trio" on TBS. Receiver operating characteristic curves evaluating the discriminatory power of $\mathrm{A} 1 \mathrm{C}$ (blue line), fasting plasma glucose (green line) and postprandial blood glucose (red line) to affect TBS.

In this study, it was observed that patients with A1C $\leq 7.0 \%$ had better TBS than those with A1C $\geq$ $7.1 \%$. An inverse relationship between A1c and TBS was proved by correlation analysis. In addition, the values of TBS are not influenced by BMI. To support the theory, that better A1c leads to better TBS and thus decreased risk of fracture, the clinical fractures were analyzed. In 14 fractured individuals greater A1c and lower TBS in comparison to non-fractured individuals was observed. In addition, previous study demonstrated that the risk of hip fracture increased among patients with higher Alc (Li et al. 2015).

A beneficial effect on TBS also showed optimal level of FPG, but there was no correlation between TBS and 2-hour PPG observed. Nevertheless, the most beneficial effect on TBS was observed when all three markers of the glycemic triad were in a satisfactory range, with slight superiority of A1c according to ROC analysis.

In our study ROC curves showed greater discriminative ability for benefit effect on TBS (AUC $=0.813$ ) against other markers of glycemic compensation. The most effective marker for evaluating of diabetic complication is $\mathrm{A} 1 \mathrm{C}$ as a marker of long-term compensation. Our data suggest the utility of A1C for evaluating also the osteoporosis risk in patients with T2DM. A1C reflects average glycaemia over approximately 3 months and has strong predictive value for diabetes complications (Albers et al. 2010, Stratton et al. 2000). Thus, A1C testing should be performed routinely in all patients with diabetes - at initial assessment and as part of continuing care.

Leidig-Bruckner et al. concluded that clinical and chemical parameters diabetes-related are not directly linked to BMD. Indeed, the occurrence of fractures is not related to the $\mathrm{T}$-score threshold, but similar in patient with low BMD and diabetes mellitus (Leidig-Bruckner et al. 2014). At the same time, many authors had explored how to evaluate the status of skeletal system and its related fracture risk in postmenopausal patients with T2DM. The aim is to supply physicians a ,non-invasive” useful tool to assess fracture risk that may help the clinician in the decision whether to prescribe or not a pharmacological treatment for osteoporosis, according to a threshold of intervention. We showed that the group patient with fractures had lower TBS and higher A1C.

This study has several limitations, which are cross-sectional design, small sample size and absence of the data on asymptomatic fractures. However, the strengths are carefully selected study population, data on clinical fractures and excluding individual with boneaffecting diabetes medications.

In conclusion, this study shows among postmenopausal females with T2DM that optimal compensation with a glycated hemoglobin value of $<7.0 \%$ is associated with better TBS. With regard to parameters of glycemic compensation we observed the greatest TBS, when all three parameters of glycemic triad in the optimal range $(\mathrm{A} 1 \mathrm{C} \leq 7.0 \%, \mathrm{FPG}<7.2 \mathrm{mmol} / 1$ and $\mathrm{PPG}<10 \mathrm{mmol} / \mathrm{l}$ ), with superiority $\mathrm{A} 1 \mathrm{C}$, the marker of long-term glycemic compensation. In addition, patients with clinical fracture had greater A1C and lower TBS in comparison to non-fractured individuals. Therefore, it is plausible that good long-term glycemic control leads to better bone microarchitecture, as measured by TBS. It is appropriate to test this hypothesis in the longitudinal, controlled study.

\section{Conclusions}

As for all diabetic complication, a good compensation is the basic principle for management of diabetes. We have showed that optimal glycemic compensation, evaluated by glycated hemoglobin, does not lead to changes in BMD but has a beneficial effect on TBS in postmenopausal women with T2DM. We can conclude that good glycemic control is required also for reduction of the risk of osteoporosis and osteoporotic fractures, because of better bone quality. Our study has various limitations it is not prospective study, we did not examine other health 
conditions which can affect bone health, we do not have the occurrence of hypoglycemic episodes, the fractures where defined only clinical, not by x-ray. Therefore, there are needed further clinical trials to conclude our results and also trials for understanding the physiological principles of good glycemic compensation on bone.

\section{Conflict of Interest}

There is no conflict of interest.

\section{Acknowledgements}

The authors received no financial support for the research, authorship, and/or publication of this article.

\section{References}

American Diabetes Association Standards of Medical Care in Diabetes 2015: Classification and Diagnosis of Diabetes. Diabetes Care 38: S8-S16, 2015.

American Diabetes Association Standards of Medical Care in Diabetes 2017: Comprehensive Medical Evaluation and Assessment of Comorbidities. Diabetes Care 40: S25-S32, 2017 a.

American Diabetes Association Standards of Medical Care in Diabetes 2017: Glycemic Targets. Diabetes Care 40: S48-S56, 2017b.

ALBERS JW, HERMAN WH, POP-BUSUI R, FELDMAN EL, MARTIN CL, CLEARY PA, WABERSKI BH, LACHIN JM: Effect of prior intensive insulin treatment during the Diabetes Control and Complications Trial (DCCT) on peripheral neuropathy in type 1 diabetes during the Epidemiology of Diabetes Interventions and Complications (EDIC) Study. Diabetes Care 33: 1090-1096, 2010.

BONACCORSI G, FILA E, MESSINA C, MAIETTI E, ULIVIERI FM, CAUDARELLA R, GRECO P, GUGLIELMI G: Comparison of trabecular bone score and hip structural analysis with RRAX $^{\circledR}$ in postmenopausal women with type 2 diabetes mellitus. Aging Clin Exp Res 29: 951-957, 2017.

BURGHARDT AJ, ISSEVER AS, SCHWARTZ AV, DAVIS KA, MASHARANI U, MAJUMDAR S, LINK TM: Highresolution peripheral quantitative computed tomographic imaging of cortical and trabecular bone microarchitecture in patients with type 2 diabetes mellitus. J Clin Endocrinol Metab 95: 5045-5055, 2010.

CECCARELLI E, GUARINO E, MERLOTTI D, PATTI A, GENNARI L, NUTI R, DOTTA F: Beyond glycemic control in diabetes mellitus: effects of incretin-based therapies on bone metabolism. Front Endocrinol (Lausanne) 4: $1-12,2013$.

DCCT-THE DIABETES CONTROL COMPLICATIONS TRIAL RESEARCH GROUP: The effect of intensive treatment of diabetes on the development and progression of long-term complications in insulin-dependent diabetes mellitus. N Engl J Med 329: 977-986, 1993.

FARR JN, DRAKE MT, AMIN S, MELTON LJ, MCCREADY LK, KHOSLA S: In vivo assessment of bone quality in postmenopausal women with type 2 diabetes. $J$ Bone Mineral Res 29: 787-795, 2014.

FURST JR, BANDEIRA LC, FAN W-W, AGARWAL S, NISHIYAMA KK, MCMAHON DJ, DWORAKOWSKI E, JIANG H, SILVERBERG SJ, RUBIN MR: Advanced glycation endproducts and bone material strength in type 2 diabetes. J Clin Endocrinol Metab 101: 2502-2510, 2016.

GENUTH S: Insights from the diabetes control and complications trial/epidemiology of diabetes interventions and complications study on the use of intensive glycemic treatment to reduce the risk of complications of type 1 diabetes. Endocr Pract 12 (Suppl 1): 34-41, 2006.

GILBERT MP, PRATLEY RE: The impact of diabetes and diabetes medications on bone health. Endocrine Rev 36: 194-213, 2015.

HANS D, GOERTZEN AL, KRIEG MA, LESLIE WD: Bone microarchitecture assessed by TBS predicts osteoporotic fractures independent of bone density: The Manitoba study. J Bone Miner Res 26: 2762-2769, 2011.

CHANDRAN M: Diabetes drug effects on the skeleton. Calcif Tissue Int 100: 133-149, 2017.

INZUCCHI SE, BERGENSTAL RM, BUSE JB, DIAMANT M, FERRANNINI E, NAUCK M, PETERS AL, TSAPAS A, WENDER R, MATTHEWS DR: Management of hyperglycemia in type 2 diabetes, 2015: A patientcentered approach: update to a position statement of the American diabetes association and the European association for the study of diabetes. Diabetes Care 38: 140-149, 2015. 
JAKUS V, RIETBROCK N: Advanced glycation end-products and the progress of diabetic vascular complications. Physiol Res 53: 131-142, 2004.

KALOUSOVA M, SKRHA J, ZIMA T: Advanced glycation end-products and advanced oxidation protein products in patients with diabetes mellitus. Physiol Res 51: 597-604, 2002.

LEIDIG-BRUCKNER G, GROBHOLZ S, BRUCKNER T, SCHEIDT-NAVE C, NAWROTH P, SCHNEIDER JG: Prevalence and determinants of osteoporosis in patients with type 1 and type 2 diabetes mellitus. BMC Endocrine Disorders 14: 33, 2014.

LESLIE WD, AUBRY-ROZIER B, LAMY O, HANS D: TBS (trabecular bone score) and diabetes-related fracture risk. J Clin Endocrinol Metab 98: 602-609, 2013.

LI C-I, LIU C-S, LIN W-Y, MENG N-H, CHEN C-C, YANG S-Y, CHEN H-J, LIN C-C, LI T-C: Glycated hemoglobin level and risk of hip fracture in older people with type 2 diabetes: a competing risk analysis of taiwan diabetes cohort study. J Bone Mineral Res 30: 1338-1346, 2015.

OEI L, RIVADENEIRA F, ZILLIKENS MC, OEI EHG: Diabetes, diabetic complications, and fracture risk. Curr Osteoporos Rep 13: 106-115, 2015.

OEI L, ZILLIKENS MC, DEHGHAN A, BUITENDIJK GHS, CASTAÑO-BETANCOURT MC, ESTRADA K, STOLK L, OEI EHG, VAN MEURS JBJ, JANSSEN JA, HOFMAN A, VAN LEEUWEN JPTM, WITTEMAN JCM, POLS HAP, UITTERLINDEN AG, KLAVER CCW, FRANCO OH, RIVADENEIRA F: High bone mineral density and fracture risk in type 2 diabetes as skeletal complications of inadequate glucose control: the rotterdam study. Diabetes Care 36: 1619-1628, 2013.

RAŠKA I JR, RAŠKOVÁ M, ZIKÁN V, ŠKRHA J: Body composition is associated with bone and glucose metabolism in postmenopausal women with type 2 diabetes mellitus. Physiol Res 66: 99-111, 2017.

SARWAR N, GAO P, SESHASAI SR, GOBIN R, KAPTOGE S, DI ANGELANTONIO E, INGELSSON E, LAWLOR DA, SELVIN E, STAMPFER M, STEHOUWER CD, LEWINGTON S, PENNELLS L, THOMPSON A, SATTAR N, WHITE IR, RAY KK, DANESH J: Diabetes mellitus, fasting blood glucose concentration, and risk of vascular disease: a collaborative meta-analysis of 102 prospective studies. Lancet 375: 2215-2222, 2010.

SCHNEIDER ALC, WILLIAMS EK, BRANCATI FL, BLECKER S, CORESH J, SELVIN E: Diabetes and risk of fracture-related hospitalization: the atherosclerosis risk in communities study. Diabetes Care 36: 1153-1158, 2013.

SILVA BC, BILEZIKIAN JP: Trabecular bone score: perspectives of an imaging technology coming of age. Arq Bras Endocrinol Metabol 58: 493-503, 2014.

STRATTON IM, ADLER AI, NEIL HAW, MATTHEWS DR, MANLEY SE, CULL CA, HADDEN D, TURNER RC, HOLMAN RR: Association of glycaemia with macrovascular and microvascular complications of type 2 diabetes (UKPDS 35): prospective observational study. BMJ 321: 405-412, 2000.

SUDORE RL, KARTER AJ, HUANG ES, MOFFET HH, LAITEERAPONG N, SCHENKER Y, ADAMS A, WHITMER RA, LIU JY, MIAO Y, JOHN PM, SCHILLINGER D: Symptom burden of adults with type 2 diabetes across the disease course: diabetes \& aging study. J Gen Intern Med 27: 1674-1681, 2012.

TINETTI ME, FRIED TR, BOYD CM: Designing health care for the most common chronic condition - multimorbidity. JAMA 307: 2493-2494, 2012.

VESTERGAARD P: Discrepancies in bone mineral density and fracture risk in patients with type 1 and type 2 diabetes-a meta-analysis. Osteoporos Int 18: 427-444, 2007.

ŽOFKOVÁ I: Bone tissue as a systemic endocrine regulator. Physiol Res 64: 439-445, 2015. 